\title{
Determinants of Breastfeeding Practices among Lactating Mothers in a Rural Block of Haryana, India
}

Anand Jain', Amit Kumar Mital', RB Jain ${ }^{3}$, Priyanka Choudhary', Gerish Atri ${ }^{5}$, Rajat Gupta ${ }^{6}$, Vijay $^{7}$, Tarun Singh ${ }^{8}$

${ }^{1}$ Senior Resident, Department of Medicine, Baba Saheb Ambedkar Medical College, New Delhi, India.

${ }^{2}$ Assistant Professor, Department of Pediatrics, World College of Medical Sciences \& Research and Hospital, Haryana, India. ${ }^{3}$ Senior Professor and Head, ${ }^{4}$ Senior Resident, $5,6,7,8$ Junior Resident, Department of Community Medicine, Pandit Bhagwat Dayal Sharma PGIMS, Rohtak, Haryana, India.

DOI: https://doi.org/10.24321/2454.325X.202105

\section{I $\quad \mathbf{N} \quad \mathbf{F}$}

\section{Corresponding Author:}

Priyanka Choudhary, Department of Community Medicine, Pandit Bhagwat Dayal Sharma PGIMS, Rohtak, Haryana, India.

E-mail Id:

drmittalpriyanka@gmail.com

Orcid Id:

https://orcid.org/0000-0001-5229-7801

How to cite this article:

Jain A, Mital AK, Jain RB, Choudhary P, Atri

G, Gupta R, Vijay, Singh T. Determinants of Breastfeeding Practices among Lactating Mothers in a Rural Block of Haryana, India. Int J Preven Curat Comm Med. 2021;7(2):1-8.

Date of Submission: 2021-05-07

Date of Acceptance: 2021-06-23

\section{$\begin{array}{llllllll}\mathbf{A} & \mathbf{B} & \mathbf{S} & \mathbf{T} & \mathbf{R} & \mathbf{A} & \mathbf{C} & \mathbf{T}\end{array}$}

Background: Human breast milk contributes to the physical growth of infants by meeting their nutritional needs and higher intelligence quotient by enhancing their brain development.

Objective: To assess the prevalence of exclusive breastfeeding and to determine the contributing factors of exclusive breastfeeding practice in a rural area of Haryana.

Methods: It was community-based cross-sectional study, conducted in a rural field practice area attached to the Department of Community Medicine of Pt BD Sharma, PGIMS, Rohtak. The study participants were infants aged 6-11 completed months and their mothers. Multistage sampling technique was used for enrolling 200 study subjects. SPSS was us for statistical analysis.

Results: 119 (59.5\%) infants were exclusively breastfed for 6 months. Homemakers were 1.37 times more likely to feed exclusively than working women. Women from joint families were 2.64 times more likely to feed exclusively than women from nuclear families. Exclusive breastfeeding had a statistically significant association with mode of delivery, breastfeeding counselling, motivation to feed till 2 years, receiving postnatal checkup, number of children, initiation of breastfeeding within 1 hour, and colostrum being given to infants. Infants given breastfeed within 1 hour had 1.12 times more chance of exclusive breastfeeding.

Conclusion: Antenatal breastfeeding counselling and home-based postnatal visits by health workers increases the practice of colostrum administration, initiation of breastfeeding within 1 hour, and exclusive breastfeeding for 6 months. Capacity building in form of training and sensitisation of hospital staff, MPHW (F), and ASHA will help increase exclusive breastfeeding among lactating mothers.

Keywords: Breastfeeding Practices, Determinants, Lactating Mothers, Rural 


\section{Introduction}

The first 1,000 days of a child's life starting from conception through age two is a crucial period for ensuring child survival, optimal growth, cognitive development, and healthy life. Being the first food of newborns, human breast milk contributes to the growth of an infant by meeting its nutritional needs and providing bioactive factors for growth. ${ }^{1}$

WHO and UNICEF Global Strategy for Infant and Young Child Feeding (IYCF) advocate for early initiation of breastfeeding within the first hour of childbirth, exclusive breastfeeding the infant with only breast milk with no supplemental liquids or solids except for liquid medicine or vitamin/ mineral supplements for 6 months and continued breastfeeding until age 2 years or longer, in addition to adequate and safe food. ${ }^{2}$ The Global breastfeeding scorecard, 2019 reports only $43 \%$ of newborns were initiated on breastfeeding within one hour of birth, only $41 \%$ of infants were exclusively breastfed for the first six months and only $45 \%$ of children were breastfed till two years of age. ${ }^{3}$ Only $41.6 \%$ of children under 3 years were breastfed within an hour of birth despite $78.9 \%$ of infants being born of institutional delivery in India ${ }^{4}$ while comparative rates of early initiation of breastfeeding for State of Haryana and District Jhajjar of Haryana were $42.3 \%$ and $28.9 \%$ respectively.5 $54.9 \%$ of children under 6 months of age were exclusively breastfed in India. ${ }^{4}$ The exclusive breastfeeding rate for children under 6 months in Haryana and district Jhajjar is $50.4 \%$ and $70.8 \%$ respectively. ${ }^{5}$

In spite of various government programmes implemented at the community level, the exclusive breastfeeding rate is less than expected. So, we intend to determine the factors which contribute to the practice of exclusive breastfeeding. Thus, this study aimed to assess the prevalence of exclusive breastfeeding and to assess the determinants of breastfeeding practice in rural areas served by $\mathrm{CHC}$ Dighal, Jhajjar, Haryana.

\section{Material and Methods}

A community-based cross-sectional study was conducted in the area of Community Health Centre ( $\mathrm{CHC}$ ) Dighal, Jhajjar, Haryana, which is the rural field practise area attached to the Department of Community Medicine, of Pt BD Sharma PGIMS, Rohtak. The study was conducted over a period of 12 months commencing from March 2019. The study population comprised of infants aged 6-11 completed months and their mothers who were willing to participate in the study. Also, infants who were apparently healthy for the last one month before enrolment for the study, with or without some minor childhood ailments were included in the study.

Infants having a history of prolonged or severe illness requiring hospitalisation, infants with congenital anomalies which affect their growth and infants separated from their mother (death, divorce, adoption) were excluded from the study.

\section{Sample Size}

Taking the prevalence of exclusive breastfeeding in Haryana as $50.4 \%$, which has been reported by NFHS $4(2015-16)^{5}$ and further taking the allowable error to be $15 \%$ of the prevalence, the sample size came out to be 178 . So for the purpose of the present study, 200 subjects were enrolled.

\section{Sampling Techniques}

Multistage sampling technique was used for enrolling the required 200 study subjects. There are 5 PHCs and 20 sub-centres under CHC Dighal, Jhajjar, Haryana. For the purpose of the study, all 20 sub-centres were selected. Two anganwadi centres (AWC) were randomly selected by lottery method from each of these sub-centre areas and thus a total of 40 AWCs were included in the study. A list of infants having six months to one year of age was prepared from each of these anganwadis and out of this list, five infants were selected by simple random sampling technique.

Home visits were made by the investigator and informed written consent was obtained from the mothers of infants for participating in the study after informing them about the purpose of the study.

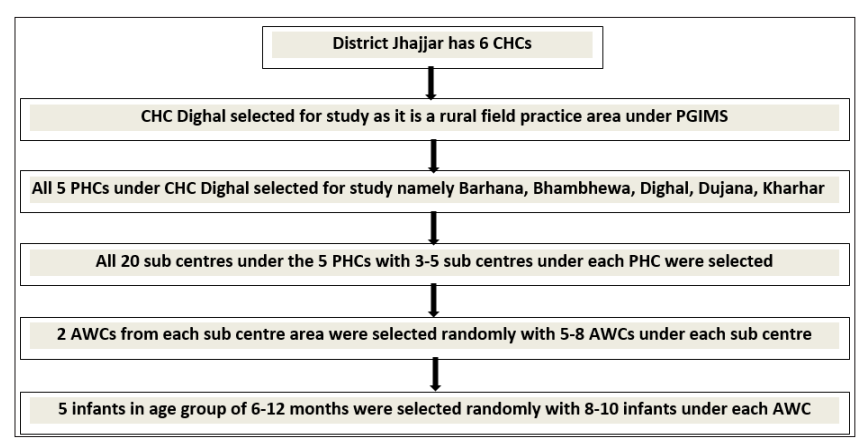

The data were collected using a pre-designed, pre-tested, semi-structured schedule which was piloted on 20 subjects for the feasibility of administration of questions, and modifications were made, before the commencement of study. For defining socio-economic status, modified BG Prasad classification $(2019)^{6}$ was used.

\section{Statistical Analysis}

The data were subjected to appropriate statistical tests using SPSS 20 (Statistical package for social sciences) software. Descriptive statistics in terms of percentages and inferential statistics as chi-square test was used for qualitative data. Binary logistic regression was applied for variables whose $p$ value was $<0.20$. 


\section{Ethics}

Ethical approval was obtained from the ethics committee of Pandit Bhagwat Dayal Sharma PGIMS, Rohtak and written informed consent was obtained from parents of the patients.

\section{Results}

Out of 200 infants, 119 (59.5\%) were exclusively breastfed for 6 months and $71.5 \%$ had initiated breastfeeding within 1 hour of delivery. As observed in Table 1, in the beginning, 161 infants were given only breastmilk but slowly many of them shifted to mixed feeding and by 6 months of age, only 119 (59.5\%) were meeting all the criteria of exclusive breastfeeding. The reasons given by mothers $(n=81)$ for not exclusively breastfeeding their child for 6 months and not initiating breastfeeding within 1 hour are depicted in Figure 1 and Figure 2 respectively. Different feed offered to infants as the first food is shown in Figure 3.

Table 2, shows the association of exclusive breastfeeding for 6 months with socio-demographic variables. On applying logistics regression, it was found that homemakers had 1.4 times more chances of feeding exclusively in comparison to working women. Likewise, women who belonged to joint families had 2.6 times more chances of feeding exclusively in comparison to those who belonged to nuclear families.

Table I.Infants given Exclusive Breastfeeding at different time intervals after Birth

\begin{tabular}{|c|c|c|}
\hline Age of Infant & Infants given only Breastmilk till this Age (n= 200) & Percentage \\
\hline First day of life & 161 & 80.5 \\
\hline At 1 week & 150 & 75 \\
\hline At 1 month & 148 & 74 \\
\hline At 3 months & 138 & 69 \\
\hline At 6 months & 119 & 59.5 \\
\hline
\end{tabular}

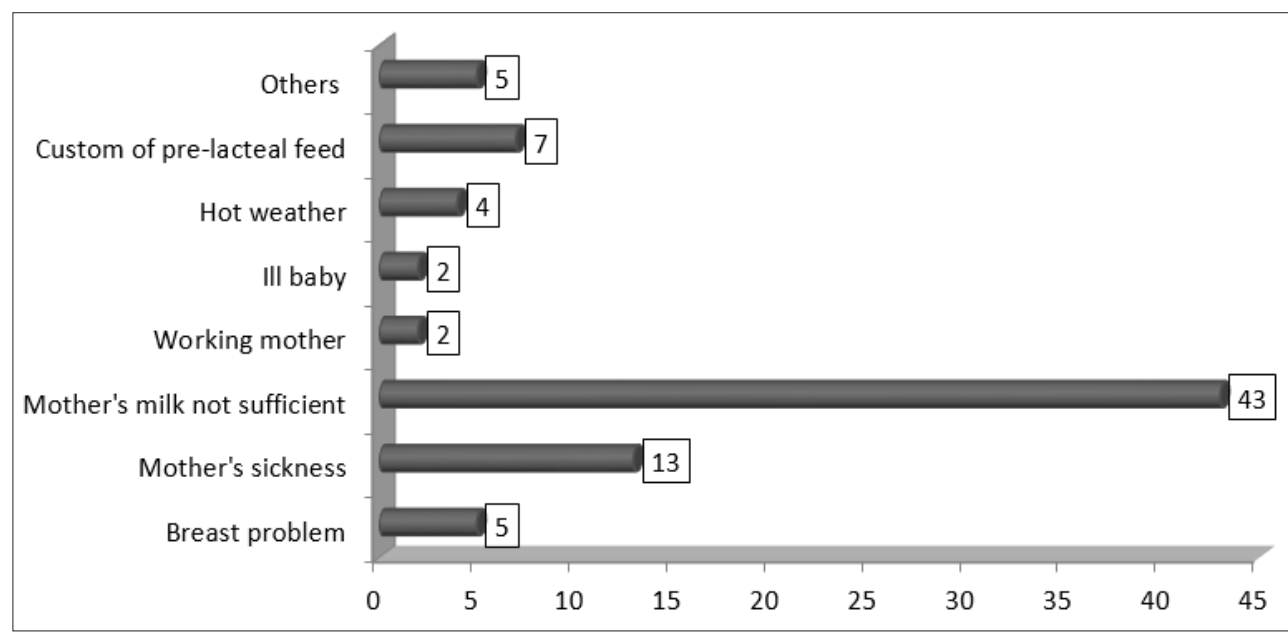

Figure I.Reasons given by Mothers for not Exclusively Breastfeeding for 6 Months

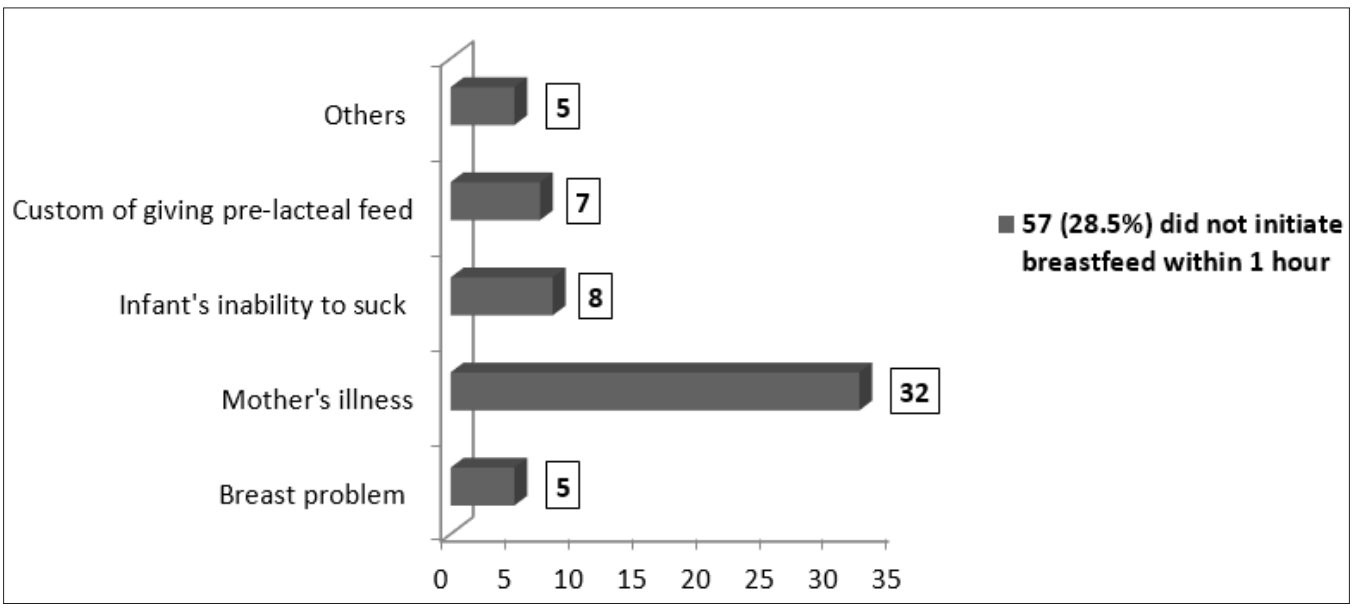

Figure 2.Reasons given by Mothers for not Initiating Breastfeeding within I hour 


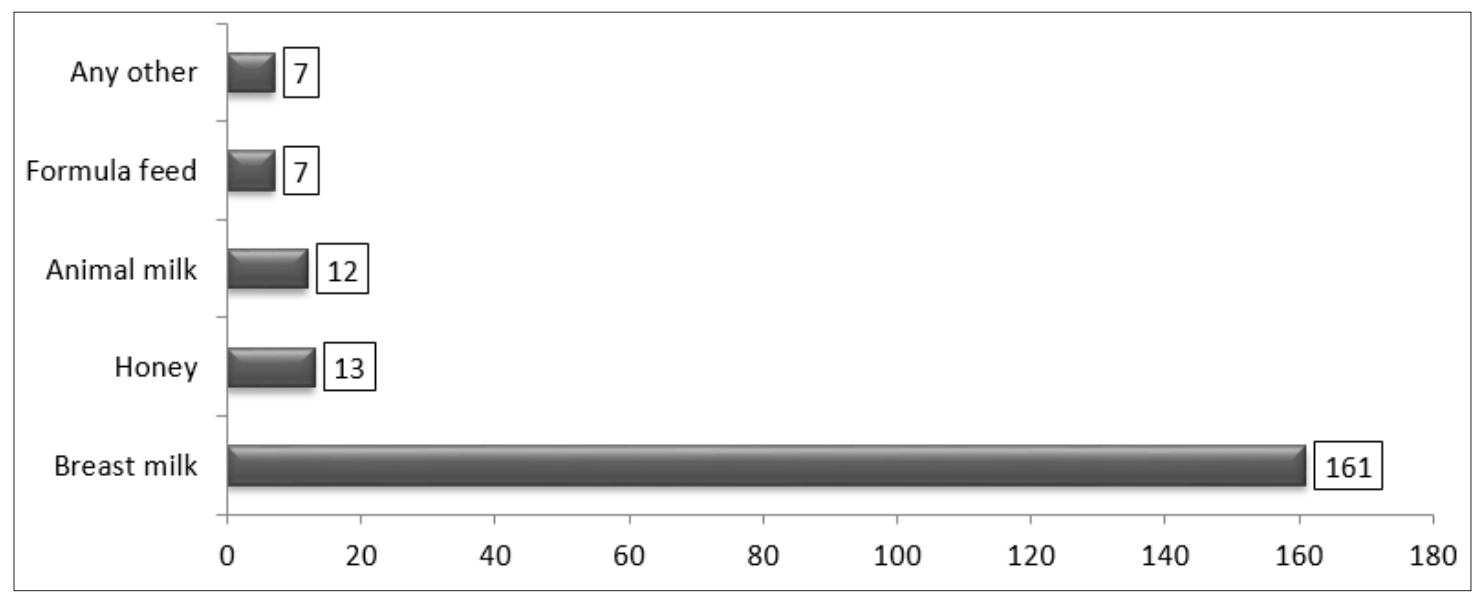

Figure 3.First Food offered to Infants after Birth

Table 2.Association of Exclusive Breastfeeding for 6 Months with Socio-demographic Variables

\begin{tabular}{|c|c|c|c|c|}
\hline Variables & $\begin{array}{c}\text { Exclusive Breastfed } \\
\text { n (\%) }\end{array}$ & $\begin{array}{l}\text { Not Exclusive Breastfed } \\
\text { n (\%) }\end{array}$ & Total & P value \\
\hline \multicolumn{5}{|l|}{ Gender of infant } \\
\hline Male & 64 (59.3) & $44(40.7)$ & 108 & 0.94 \\
\hline Female & $55(59.8)$ & $37(40.2)$ & 92 & \\
\hline \multicolumn{5}{|c|}{ Age of mother (years) } \\
\hline$<35$ & 117 (60.3) & 77 (39.7) & 194 & 0.23 \\
\hline$>35$ & $2(33.3)$ & $4(66.7)$ & 6 & \\
\hline \multicolumn{5}{|c|}{ Education of mother } \\
\hline Illiterate & $8(53.3)$ & $7(46.7)$ & 15 & 0.61 \\
\hline Literate & $111(60.0)$ & $74(40.0)$ & 185 & \\
\hline \multicolumn{5}{|c|}{ Mother's occupation } \\
\hline Homemaker & $114(60.6)$ & $74(39.4)$ & 188 & 0.19 \\
\hline Working woman & $5(41.7)$ & $7(58.3)$ & 12 & \\
\hline \multicolumn{5}{|c|}{ Socioeconomic Status } \\
\hline Upper & $6(42.9)$ & $8(57.1)$ & 14 & 0.57 \\
\hline Upper middle & $25(67.6)$ & $12(32.4)$ & 37 & \\
\hline Middle & $28(63.6)$ & $16(36.4)$ & 44 & \\
\hline Lower Middle & 39 (61.9) & $24(38.1)$ & 63 & \\
\hline Lower & $21(50)$ & $21(50)$ & 42 & \\
\hline \multicolumn{5}{|l|}{ Type of family } \\
\hline Joint & $95(57.2)$ & $71(42.8)$ & 166 & 0.15 \\
\hline Nuclear & $24(70.6)$ & $10(29.4)$ & 34 & \\
\hline Total & 119 (59.5) & 81 (40.5) & $200(100)$ & \\
\hline
\end{tabular}

Table 3, shows the association of exclusive breastfeeding of a child till 6 months with obstetric factors among lactating mothers. In comparison to hospital stay of mothers for more than 2 days, women who were discharged after 2 days of delivery, on the next day of delivery, and on the same day of delivery had 3.7 times, 1.2 times, and 1.6 times more chances of exclusive breastfeeding respectively. Figure 4 depicts the postnatal home visits given to mothers by health care workers after delivery. The types of problems faced by mothers while breastfeeding the baby in public places is depicted in Figure 5. 
Table 3.Association of Exclusive Breastfeeding for 6 Months with Obstetric Factors among Lactating Mothers

\begin{tabular}{|c|c|c|c|c|}
\hline Variables & $\begin{array}{l}\text { Exclusive breastfed } \\
\qquad \mathrm{n}(\%)\end{array}$ & $\begin{array}{l}\text { Not Exclusive breastfed } \\
\qquad \mathrm{n}(\%)\end{array}$ & Total & $P$ value \\
\hline \multicolumn{5}{|l|}{ Mode of delivery } \\
\hline NVD & $106(65.4)$ & $56(34.6)$ & 162 & 0.00 \\
\hline $\mathrm{c} / \mathrm{s}$ & $13(34.2)$ & $25(65.8)$ & 38 & \\
\hline \multicolumn{5}{|c|}{$\begin{array}{l}\text { Spacing between last two children ( } n=110 \text {, having two or more than two children) } \\
\text { Note: } 84 \text { mothers had } 1 \text { child and } 6 \text { infants were outcome of multiple pregnancy }\end{array}$} \\
\hline$<2$ year & $14(50)$ & $14(50)$ & 28 & 0.39 \\
\hline 2-3 year & $33(80.5)$ & $8(19.5)$ & 41 & \\
\hline$>3$ year & $26(63.4)$ & $15(36.6)$ & 41 & \\
\hline \multicolumn{5}{|c|}{ Breastfeeding counselling during ANC } \\
\hline Yes & $101(63.5)$ & $58(36.5)$ & 159 & 0.02 \\
\hline No & $18(43.9)$ & $23(56.1)$ & 41 & \\
\hline \multicolumn{5}{|c|}{ Day of discharge after delivery } \\
\hline Same day & $27(71)$ & $11(29)$ & 38 & 0.01 \\
\hline Next day & $33(60)$ & $22(40)$ & 55 & \\
\hline After 2 days & $40(67.8)$ & $19(32.2)$ & 59 & \\
\hline More than 2 days & $19(39.6)$ & $29(60.4)$ & 48 & \\
\hline \multicolumn{5}{|c|}{ Mother's motivation to feed till 2 years } \\
\hline Fully motivated & $88(68.2)$ & $41(31.8)$ & 129 & 0.00 \\
\hline Partially motivated & $26(52)$ & $24(48)$ & 50 & \\
\hline Not motivated enough & $5(23.8)$ & $16(76.2)$ & 21 & \\
\hline \multicolumn{5}{|c|}{ Last child exclusively fed for 6 months $(n=110)$} \\
\hline Yes & $67(72.8)$ & $25(27.2)$ & 92 & 0.00 \\
\hline No & $6(33.3)$ & $12(66.7)$ & 18 & \\
\hline \multicolumn{5}{|l|}{ Received postnatal check up } \\
\hline Yes & $115(61.2)$ & $73(38.8)$ & 188 & 0.07 \\
\hline No & $4(33.3)$ & $8(66.7)$ & 12 & \\
\hline \multicolumn{5}{|l|}{ Number of children } \\
\hline 1 & $46(54.1)$ & $39(45.9)$ & 85 & 0.01 \\
\hline 2 & $53(57.6)$ & $39(42.4)$ & 92 & \\
\hline 3 & $14(87.5)$ & $2(12.5)$ & 16 & \\
\hline 4 & $2(66.7)$ & $1(33.3)$ & 3 & \\
\hline 5 & $4(100)$ & 0 & 4 & \\
\hline
\end{tabular}

Table 4 shows the association of exclusive breastfeeding with infant feeding practices. Infants given breastfeed within 1 hour had 1.12 times more chance of exclusive breastfeeding than infants who were not given breastfeed within 1 hour. Out of 185 infants who were given colostrum, 26 (14.1\%) were given pre-lacteal feeds like honey, animal milk, formula feed etc. before giving them breast milk. Among infants who were not given colostrum feeding, $86.7 \%$ were given pre-lacteal feeds. The association between colostrum feeding and the first food offered to infants was found to be statistically significant $(p=0.00)$. 


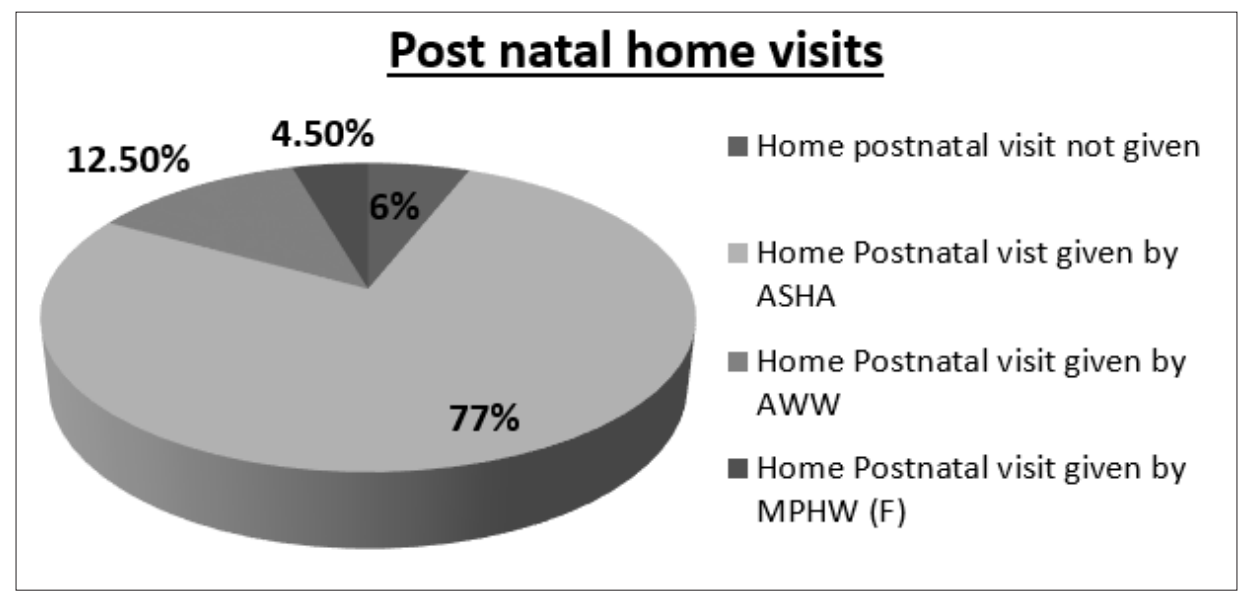

Figure 4.Postnatal Home Visits given to Mothers after Delivery

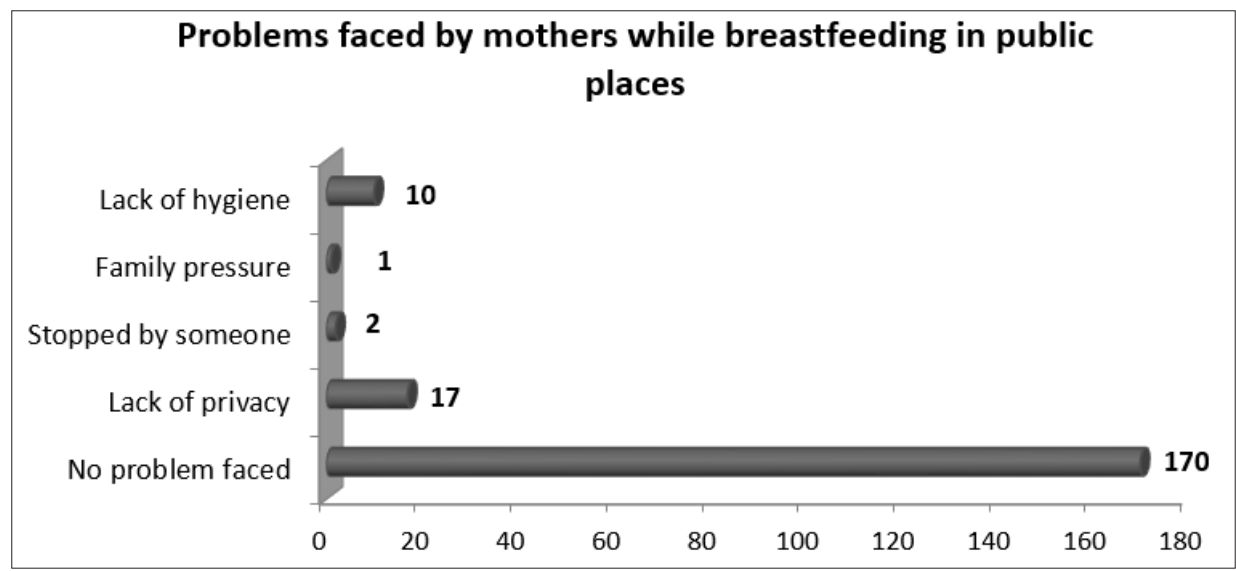

Figure 5.Problems faced by Mothers while Breastfeeding in Public Places

Table 4.Association of Exclusive Breastfeeding for 6 Months with Other Infant Feeding Practices among Lactating Mothers

\begin{tabular}{|c|c|c|c|c|}
\hline Variables & $\begin{array}{c}\text { Exclusive Breastfed } \\
\text { n (\%) }\end{array}$ & $\begin{array}{c}\text { Not Exclusively Breastfed } \\
\text { n (\%) }\end{array}$ & Total & $P$ value \\
\hline \multicolumn{5}{|c|}{ Initiation of BF within 1 hour } \\
\hline Yes & $99(69.2)$ & $44(30.8)$ & 143 & 0.00 \\
\hline No & $20(35.1)$ & $37(64.9)$ & 57 & \\
\hline \multicolumn{5}{|l|}{ Colostrum given } \\
\hline Yes & $118(63.8)$ & $67(36.2)$ & 185 & 0.00 \\
\hline No & $1(6.7)$ & $14(93.3)$ & 15 & \\
\hline \multicolumn{5}{|c|}{ Type of baby feeding schedule $(n=185)$} \\
\hline Demand feeding & $36(59)$ & $25(41)$ & 61 & 0.47 \\
\hline Interval feeding & $80(64.5)$ & $44(35.5)$ & 124 & \\
\hline \multicolumn{5}{|l|}{ Night feeding ( $n=185$ ) } \\
\hline Yes & $114(64.4)$ & $63(35.6)$ & 177 & 0.05 \\
\hline No & $2(25)$ & $6(75)$ & 8 & \\
\hline
\end{tabular}

\section{Discussion}

The prevalence of exclusive breastfeeding was found to be
$59.5 \%$ in the present study, with an almost similar proportion of male and female infants (59.3\% and $59.8 \%$ respectively) receiving exclusive breastfeeding for the complete 6 
months. In Nagpur, Patel $(2018)^{7}$ reported $71 \%$ and $96 \%$ exclusive breastfeeding in control and intervention groups respectively. Anwar $(2014)^{8}$ found a $25.3 \%$ prevalence of exclusive breastfeeding in the 0-6 months cohort in Varanasi. The prevalence for 6 months exclusive breastfeeding was found to be $71.0 \%$ by Manyeh $(2020)^{9}$ in Ghana, $47 \%$ by Woldeamanuel $(2020)^{10}$ in Ethiopia and $62.3 \%$ (at 5 months) by Milinco (2019) ${ }^{11}$ in Italy. The difference in the prevalence of exclusive breastfeeding in different studies can be attributed to different socioeconomic settings and the varied cultures of these places.

The decline in exclusive breastfeeding practices at different ages of infants was similar to a study done in Andhra Pradesh by Meshram (2012), ${ }^{16}$ where exclusive breastfeeding in the first month declined to $86 \%$ at 3 months, $46 \%$ at 5 months of age, and $41 \%$ at 6 months. In an Italian study by Cinelli (2018), ${ }^{12}$ exclusively breastfed infants were $69.5 \%(n=321)$ at birth and $19.9 \%(n=92)$ at 6 months of age.

\section{Reasons for not Exclusively Breastfeeding}

Similar to our study, Ratnayake (2018) $)^{13}$ found that the main reason for early cessation of exclusive breastfeeding was the mother's thinking that breast milk was not sufficient for the growing needs of the baby (52.9\%).

\section{Exclusive Breastfeeding and Literacy Status of Mothers}

Similar to this study, Cinelli (2018), ${ }^{12}$ Acharya (2015), ${ }^{17}$ and Berhanu (2015) ${ }^{15}$ also found that maternal education was positively associated with the duration of breastfeeding. This could be due to a better understanding of health issues and better accessibility of literate mothers to literature regarding child-rearing practices.

\section{Exclusive Breastfeeding and Occupational Status of Mothers}

In a study conducted by Ratnayake (2018), ${ }^{13}$ Berhanu (2015), ${ }^{15}$ and Sasaki (2010), ${ }^{18}$ it was observed that working mothers were more often associated with cessation of exclusive breastfeeding. Contrary to this study, Manyeh $(2020)^{9}$ found a significant association between occupation and exclusive breastfeeding.

\section{Exclusive Breastfeeding and Mode of Delivery}

Infants born by normal vaginal delivery showed a higher prevalence of exclusive breastfeeding for 6 months and early initiation of breastfeeding within 1 hour of birth as compared to those who were delivered by cesarean section. This was in line with the findings in the research of Woldeamanuel $(2020)^{10}$ and Elyas $(2017)^{14}$ who found that spontaneous vaginal delivery was a significant factor in enhancing exclusive breastfeeding.

\section{Home-based Postnatal Care Visits and Exclusive Breastfeeding among Mothers}

Exclusive breastfeeding was $61.2 \%$ among mothers who received home-based postnatal care visits as compared to $33.3 \%$ among those who were not paid any such visit. The finding suggested a positive impact of home-based postnatal care visits, up to 42 nd day after delivery, on exclusive breastfeeding practices.

\section{Colostrum Feeding and Exclusive Breastfeeding}

A significantly higher rate of exclusive breastfeeding was seen in infants who had colostrum feeding (63.8\%) as compared to those who were not given colostrum (6.7\%). The social customs of discarding colostrum and giving prelacteal feeds still acted as a hindrance for colostrum feeding. Similar observations were made by Awasthia $(2019)^{19}$ in their study in Uttar Pradesh who found that pre-lacteal feeding was a major barrier to exclusive breastfeeding.

\section{Early Initiation of Breastfeeding and Exclusive Breastfeeding}

Similar to our study, Ratnayake $(2018)^{13}$ in Sri Lanka also found that failure in timely initiation of breastfeeding was associated with premature discontinuation of exclusive breastfeeding.

\section{Motivation of Mothers for Continued Breastfeeding and Exclusive Breastfeeding}

The study showed that motivation played a significant role in exclusive breastfeeding practice. Similarly Ratnayake $(2018)^{13}$ also found that mothers' poor attitude towards exclusive breastfeeding (Adjusted OR 2.98) was itself associated with its early cessation.

\section{Limitations of Study}

A causal relationship of exclusive breastfeeding with obstetric factors or infant feeding practices could not be established. Some part of the study questions relied on the memory of respondents which may have introduced recall bias in the findings.

\section{Conclusion}

The prevalence of exclusive breastfeeding till 6 months in the rural area was $59.5 \%$. The factors affecting the same were birth order of infant, antenatal counselling on exclusive breastfeeding, mode of delivery, duration of mother's stay in hospital after delivery, colostrum feeding, early initiation of breastfeeding within 1 hour of birth, and motivation of mothers to continue breastfeeding for 2 years. Antenatal breastfeeding counselling to young married women and expectant mothers along with home-based postnatal visits by health workers will increase their self- 
confidence, knowledge, and awareness about maintenance of good habits (advantages of colostrum administration and exclusive breastfeeding till 6 months, and about harms of pre-lacteals and mixed feeding). Capacity building in the form of training and sensitisation of hospital staff (institutional deliveries), MPHW (F), and ASHA (homebased postnatal care visits) will help increase exclusive breastfeeding among lactating mothers.

\section{Financial Support: None}

\section{Conflict of Interest: None}

\section{References}

1. UNICEF [Internet]. Breastfeeding A Mother's Gift, For Every Child. New York: United Nations Children's Fund (UNICEF); 2018. Available from: https://data.unicef. org/resources/breastfeeding-a-mothers-gift-for-everychild/

2. World Health Organization, United Nations Children's Fund. Global strategy for infant and young child feeding. Geneva: World Health Organization; 2003. [Google Scholar]

3. World Health Organization [Internet]. Global breastfeeding scorecard, 2019: increasing commitment to breastfeeding through funding and improved policies and programmes. Available from: https://apps.who. int/iris/handle/10665/326049

4. Ministry of Health and Family Welfare [Internet]. National Family Health Survey, India, 2015-16: India. Mumbai: IIPS; 2017. Available from: http://rchiips.org/ NFHS/NFHS-4Reports/India.pdf

5. International Institute for Population Sciences. National Family Health Survey, India, 2015-16: Haryana. Mumbai: IIPS; 2017.

6. Pandey VK, Aggarwal P, Kakkar R. Modified BG Prasad socio-economic classification, update - 2019. Ind J Comm Health. 2019;31(1):123-5. [Google Scholar]

7. Patel A, Kuhite P, Puranik A, Khan SS, Borkar J, Dhande L. Effectiveness of weekly cell phone counselling calls and daily text messages to improve breastfeeding indicators. BMC Pediatrics. 2018;18(1):337. [PubMed] [Google Scholar]

8. Anwar F, Srivastava RK, Singh SP. Evaluation of infant and young child feeding through a Trial for Improved Practices (TIPS) in rural Varanasi. Ind J Comm Health. 2014;26(2):130-6. [Google Scholar]

9. Manyeh AK, Amu A, Akpakli DE, Williams JE, Gyapong $M$. Estimating the rate and determinants of exclusive breastfeeding practices among rural mothers in Southern Ghana. Int Breastfeed J. 2020 Feb 7;15(1):7. [PubMed] [Google Scholar]

10. Woldeamanuel BT. Trends and factors associated to early initiation of breastfeeding, exclusive breastfeeding and duration of breastfeeding in Ethiopia: evidence from the Ethiopia Demographic and Health Survey 2016. Int Breastfeed J. 2020;15(1):3. [PubMed] [Google Scholar]

11. Goswami S, Khanna P, Verma R, Chayal V. Assessment of breastfeeding practices among lactating mothers: a cross-sectional study. Int J Comm Med Public Health. 2018;5(6):2542-7. [Google Scholar]

12. Cinelli G, Fabrizi M, Shashaj B, Matteis GD, Bedogni G, Comparcola D, Ruggeri S, Nobili V, Manco M. Infant feeding practices in the first year of life in a metropolitan Italian Cohort. J Food Nutr Res. 2018;6(2):82-8. [Google Scholar]

13. Ratnayake HE, Rowel D. Prevalence of exclusive breastfeeding and barriers for its continuation up to six months in Kandy district, Sri Lanka. Int Breastfeed J. 2018;13(1):36. [Google Scholar]

14. Elyas L, Mekasha A, Admasie A, Assefa E. Exclusive breastfeeding practice and associated factors among mothers attending private pediatric and child clinics, Addis Ababa, Ethiopia: a cross-sectional study. Int J Pediatr. 2017:1-9. [PubMed] [Google Scholar]

15. Berhanu M, Zemene W, Mekonnen M. Prevalence and associated factors of nonexclusive breastfeeding to infants within the first 6 months in Gondar town, Northwest Ethiopia, 2014. Adv Nurs. 2015;142319:1-7. [Google Scholar]

16. Meshram II, Laxmaiah A, Venkaiah K, Brahmam GN. Impact of feeding and breastfeeding practices on the nutritional status of infants in a district of Andhra Pradesh, India. Natl Med J India. 2012;25(4):201-6. [PubMed] [Google Scholar]

17. Acharya $P$, Khanal V. The effect of mother's educational status on early initiation of breastfeeding: further analysis of three consecutive Nepal Demographic and Health Surveys. BMC Public Health. 2015;15(1):1069. [PubMed] [Google Scholar]

18. Sasaki Y, Ali M, Kakimoto K, Saroeun O, Kanal K, Kuroiwa C. Predictors of exclusive breast-feeding in early infancy: a survey report from Phnom Penh, Cambodia. J Pediatr Nurs. 2010;25(6):463-9. [PubMed] [Google Scholar]

19. Awasthi S, Verma T, Sanghvi T, Frongillo EA. Path to severe acute malnutrition in children below 2 years of age: Findings of qualitative research in Uttar Pradesh, North India. Clin Epi Global Health. 2019;7(2):246-52. [Google Scholar] 